\title{
REFORMA DEL SECTOR DEFENSA EN ÁFRICA: EL CASO DE NIGERIA DURANTE LA CUARTA REPÚBLICA, 1999-2016*
}

\author{
Eduardo A. Carreño Lara \\ Universidad de Chile \\ ecarreno@uchile.cl
}

\section{RESUMEN}

El objetivo de este artículo es analizar la Reforma del Sector Defensa (RSD) en Nigeria durante la Cuarta República, en especial, su impacto en cuatro áreas estratégicas: relaciones cívico-militares, diseño de estructura de la fuerza, entrenamiento y gestión estratégica del personal militar y modernización de los sistemas de armas. Asimismo, se evalúa el rol de los militares en la política africana desde la independencia, como también la organización de las Fuerzas Armadas de Nigeria durante los períodos colonial y postcolonial. Finalmente, esta investigación revisa las consecuencias de la RSD y su impacto en la política exterior nigeriana hacia África.

Palabras clave: Reforma militar, Defensa nacional, Militares, Nigeria.

* Este trabajo se basa en la tesis doctoral del autor, la cual se desarrolla en el Departamento de Ciencia Política y Relaciones Internacionales (Grupo de Estudios Africanos) de la Universidad Autónoma de Madrid (Becario de la Comisión Nacional de Investigación Científica y Tecnológica de Chile, 2015-2017). 


\title{
REFORM OF THE DEFENSE SECTOR IN AFRICA: THE CASE OF NIGERIA DURING THE FOURTH REPUBLIC, 1999-2016
}

\begin{abstract}
The aim of this article is to analyze the reform of the Defense Sector in Nigeria during the Fourth Republic, with emphasis on the impact it had on four strategic areas: civil-military relations, force structure design, training and strategic management of military personnel and modernization of weapon systems. Furthermore, this text evaluates the role the military have played in African politics since independence, as well as the organization of the Nigerian Armed Forces during the colonial and post-colonial period. Finally, this research reviews the consequences of the reform of the Defense Sector and the impact it had on Nigeria's foreign policy towards Africa.
\end{abstract}

Keywords: Military reform, National defense, Military, Nigeria. 


\section{INTRODUCCIÓN}

Comprender las dictaduras en Nigeria implica apelar a un amplio marco analítico que incluya no solo las motivaciones que hay detrás de los golpes de Estado. Es necesario conocer también aquellas contingencias que propician su emergencia y, recientemente, los instrumentos constitucionales y democráticos que permiten mantener a los militares fuera de la actividad política.

En este sentido, los últimos años han sido analizadas las razones que han impedido consolidar una gobernanza política ${ }^{1}$ en Nigeria, concluyéndose que esta se encuentra determinada principalmente por el legado de años de interregno militar. Durante estos oscuros períodos (1966-1979; 19831999) se gobernó al margen del imperio de la ley y el respeto de los derechos humanos. También emergió una cultura que veía en la corrupción el único principio rector de la gestión de los asuntos públicos (Ezenyili 2012).

La transición política iniciada en 1999 dio indiscutiblemente un nuevo impulso a la democracia en Nigeria, disfrutando esta actualmente de la estabilidad institucional más larga desde su independencia. A partir del gobierno de Olusegun Obasanjo (1993-2003, 2003-2007) se han dado pasos importantes en el fortalecimiento de la gobernanza política (Ogundiya 2010), destacando entre estos un mayor respeto a los derechos humanos y una mayor participación de la sociedad civil en la actividad política.

Del mismo modo, tanto la Asamblea Nacional como la Corte Suprema están desempeñando un rol mucho más activo, alcanzando aceptables niveles eficacia en el cumplimiento de sus prerrogativas constitucionales al momento de hacer frente a un dominante Poder Ejecutivo (Adelegan 2012). Además, el gobierno de Nigeria ha superado la condición de paria en el sistema internacional, la cual se remontaba a mediados de la década de los noventa cuando fue expulsado temporalmente de la Commonwealth como resultado de los sistemáticos atropellos a los derechos humanos.

Sin embargo, todo ello no ha borrado el triste legado de las dictaduras militares, careciendo todavía parte importante de los nigerianos de acceso

1 Se entenderá por gobernanza política la inclusión de actores sociales y ciudadanos en las redes de elaboración, implantación y evaluación de políticas públicas, todo ello dado en el marco de un sistema político democrático en donde prima el respeto de los derechos humanos, el imperio de la ley y la justicia social (Adelegan 2012, Ezenyili 2012). 
a los servicios públicos (Oke 2010). Del mismo modo, se propició la "modernización" de las instituciones estatales, lo cual tendió a establecer gobiernos carentes de vinculación con su propia sociedad, ajenos a los escrutinios populares y muy sensibles a las exigencias de las entidades internacionales (por ejemplo, Banco Mundial y Fondo Monetario Internacional). En otras palabras, se prestó poca atención a la ciudadanía y a las cuestiones del Estado como "comunidad política" (Boege et.al. 2009).

Además, en términos generales, la democratización vivida en Nigeria se ha limitado al desarrollo de elecciones con cierta periodicidad, en una visión que acota la noción de democracia a un mero proceso; obviándose una transformación de fondo que implica dos dimensiones inseparables: por una parte, un cambio en la cultura política; y por otra, la legitimación de las instituciones del Estado de Derecho (Carreño 2016). Dentro de estas últimas, el sometimiento del poder militar al poder civil continúa siendo el talón de Aquiles de una todavía frágil institucionalidad política.

Por lo anterior, el objetivo de este artículo es analizar los éxitos y fracasos de la reforma del sector defensa impulsada en Nigeria durante la Cuarta República, en particular, los ambiciosos planes tendientes a desarrollar una institucionalidad democrática en los siguientes ámbitos: conducción de las relaciones civiles-militares; diseño de la fuerza; entrenamiento y gestión estratégica del personal militar; y modernización de los sistemas de armas.

\section{LOS MILITARES EN LA POLÍTICA AFRICANA: BREVES APUNTES $^{2}$}

En medio del sinnúmero de crisis institucionales que vive África, los militares han intervenido en política y transformado en gobernantes. Han justificado este rol arguyendo cumplir la misión (mesiánica) de salvar a sus respectivos países del abismo de la incompetencia civil. En este sentido, los militares han mantenido un discurso patriótico y declarado como objetivo librar al continente de políticos corruptos, ineficientes e ineficaces tal como se hizo durante la descolonización.

En este sentido, los militares africanos articularon un discurso que promete, primero, crear sociedades más equitativas, estables y probas; segundo, consolidar la unidad nacional y la estabilidad política; y tercero, terminar la mala gestión gubernamental. A juicio de Agbese (2004), estas

2 Para un análisis pormenorizados de la influencia de los militares en los sistemas políticos de África, véase Carreño (2016), Houngnikpo (2013) Assensoh y AlexAssensoh (2001), Edgerton (2002). 
promesas responden a una particular visión de las instituciones castrenses en relación al ejercicio del poder político, la cual lleva a estas -primeroa una comprensión muy simplista de la naturaleza del subdesarrollo que enfrentan las naciones africanas, concluyendo que el problema radica solo en una elite civil que por su indisciplina, codicia y falta de patriotismo pone en peligro el país. Segundo, los militares han sobreestimado su capacidad para hacer frente a los problemas socioeconómicos de África. Por último, las promesas responden simplemente a la necesidad de conseguir legitimidad en consideración de que no cuentan con un mandato constitucional para ejercer tareas de gobierno.

Además, los gobiernos militares africanos rara vez han puesto énfasis en una institucionalización, es decir, en la legitimación de una nueva estructura política estable y compleja que otorga grados de autonomía de decisión a sus diferentes subsistemas. El pretorianismo en África se manifiesta en la presencia de funcionarios que muestran un desprecio por el proceso político, sin embargo, conscientes de su aislamiento de la sociedad, las juntas militares -particularmente aquellas que buscan su perpetuación en el poder o aquellas de carácter marxista- han buscado la legitimación popular a través de la dictación de nuevos ordenamientos constitucionales, la creación de partidos políticos o la celebración de plebiscitos que vienen a afianzar "legalmente" a las fuerzas armadas como únicos actores dominantes (Decalo 1990).

Por otra parte, la injerencia política de las fuerzas armadas en África se explica a partir de varias teorías, las cuales -de acuerdo a Eleazu (1973)_ pueden agruparse en torno a dos argumentos centrales. Primero, los militares africanos, como continuidad de los ejércitos coloniales europeos, son instituciones modernas por cuanto absorbieron una ética puritana, el profesionalismo, un espíritu nacionalista y una cohesión de grupo que los hará actuar conjuntamente y de manera decisiva en el quehacer militar y, de ser necesario, en las funciones políticas (Janowitz 1964). En otras palabras, son las instituciones más "modernas" de las sociedades africanas tanto a nivel cultural, como en capacidad de gestión de recursos tecnológicos (por ejemplo, equipamiento militar)

Del mismo modo, una segunda corriente de pensamiento sostiene que los golpes de Estado en África no pueden explicarse por las características de la organización militar, sino por la naturaleza de la sociedad por cuanto si sus instituciones políticas son ineficaces en la mediación de los conflictos, entonces los militares u otras fuerzas sociales pueden incidir en política (Finer 1962). En efecto, esta escuela sostiene que ante una situación de fragilidad institucional solo los militares son capaces de salvar el Estado 
e impulsar la modernización, por cuanto si no existe ni legitimidad institucional ni cohesión nacional, solo queda sustituir la política por el uso de la fuerza.

Posteriormente, durante los años noventa, una ola de reformas políticas tuvo por objeto acabar con las dictaduras militares africanas, derrocándose a muchos gobernantes ya sea a partir de exitosas revoluciones civiles o por medio de la insurgencia de otros miembros de las fuerzas armadas que prometían una rápida democratización del país (por ejemplo, Malí). Sin embargo, la desmilitarización de la política africana ha sido relativa, por cuanto la experiencia poscolonial del quebrantamiento militar de la institucionalidad democrática ha creado una cultura política que considera legítimas estas acciones y lleva a población civil a tolerarlas e, incluso, aplaudirlas (Clark 2010).

Por otra parte, tras la Guerra Fría y el colapso institucional de varios países, es necesario ampliar el análisis de los parámetros de una intervención de los militares en la política africana. En efecto, es imperioso estudiar no solo el uso de la fuerza por parte de las instituciones castrenses, sino también por grupos armados no tradicionales cuyo claro propósito es alterar el sistema político de un país a través de mecanismos no ortodoxos (Carreño 2016). $\mathrm{Su}$ argumento central habla de la indolencia del Estado ante la seguridad de un sector de la población, lo cual lleva a este a establecer sus propios contingentes armados a fin de responder violentamente ante cualquier ataque de otro grupo étnico o institución estatal.

De este modo, se identifican varias formas no tradicionales de injerencia política por parte de diferentes grupos armados, las cuales deben ser tratadas y analizadas en virtud de sus efectos en el ejercicio de las tareas gubernamentales, las relaciones de poder, la paz y la estabilidad social. Destacan entre estas el secesionismo, los señores de la guerra, el populismo, el vigilantismo, las milicias étnicas y el mercenarismo (Kieh 2004, Nathan 1997, Reno 2011).

En suma, los gobiernos militares africanos han minado los cimientos democráticos tradicionales de convivencia cívica y responsabilidad política, propiciando en estas sociedades una mentalidad de hostigamiento y conflicto, de intereses e iniciativas alejadas de la búsqueda del bien común, la carencia de un Estado de Derecho, la completa intransigencia en las posiciones políticas, la arrogancia de quienes detenta el poder y el desprecio por el diálogo y el acuerdo (Carreño 2016). 


\section{LOS MILITARES EN LA POLÍTICA DE NIGERIA, 1966-1999³}

Para entender la predisposición de los militares nigerianos a intervenir en política, es necesario retrotraerse a la constitución de las instituciones militares coloniales a comienzos del siglo XX. Hacia 1900, gracias al trabajo del Royal West African Frontier Force (RWAFF), los británicos logran ocupar y controlar la totalidad del territorio de Nigeria, estableciéndose dos batallones en el norte y dos batallones en el sur. Estos acompañaron a la administración colonial en todo el territorio y permitieron reforzar la autoridad.

Esta institucionalidad era compatible con la política del gobierno indirecto, el cual tenía por objetivo marcar las diferentes identidades étnicas a fin de impedir el desarrollo de un arraigo nacional. Además, permitió a los británicos manipular a los grupos étnicos, enfrentarlos y reducir los espacios de cooperación entre ellos. Esto se tradujo, finalmente, en un debilitamiento de la resistencia a la dominación colonial (Carreño 2016).

En materia militar, el reclutamiento llevado a cabo por el ejército colonial contribuyó a la polarización, por cuanto los británicos fijaron como criterio de ingreso consideraciones políticas, sociales y étnicas. En efecto, la administración colonial definió algunas regiones del territorio como cuna de la resistencia, siendo particularmente problemático el sudeste de Nigeria, por lo cual, todos sus habitantes (mayoritariamente Ibos) fueron considerados políticamente no aptos para sumarse a los cuerpos armados. Se favoreció, así, la incorporación de los Hausa-Fulani, quienes se ubicaban en los territorios norteños. Esto, por su parte, implicó un problema en sí por cuanto la mayoría de los alistados de esta región eran esclavos emancipados o fugitivos, lo cual llevó a quienes habían nacido libres a mostrarse renuentes a unirse al ejército (Carreño 2016).

Con el estallido de las dos guerras mundiales, Gran Bretańa necesitó imperiosamente ampliar los criterios de reclutamiento a fin de contar con más dotación, lo cual significó la aceptación en el ejército de voluntarios provenientes de todas las regiones de Nigeria. En este contexto, los oficiales británicos intencionalmente azuzaron durante el período de entrenamiento de las tropas la tensión, la rivalidad y el antagonismo entre las distintas etnias, separando posteriormente a estas en diferentes compañías y pelotones de acuerdo a su origen. Asimismo, mostraron racismo y desprecio hacia sus compañeros de armas africanos, con quienes simplemente no existía

3 Para un análisis pormenorizado de la influencia de los militares en los sistemas políticos de África, véase Carreño (2016). 
interacción social.

Poco antes de la independencia, el gobierno colonial intentó otorgar un carácter nacional al ejército de Nigeria, para lo cual adoptó en 1958 un plan de reclutamiento basado en cuotas: el 50\% del contingente militar provendría de la región norte (Hausa-Fulani), el 25\% de las localidades ubicada al sudeste (Ibos) y el 25\% restante de la región de occidental (Yoruba) (Carreño 2016). Sin embargo, este plan fracasó por cuanto los líderes militares nigerianos compartían importantes atributos con sus homólogos coloniales: primero, el desprecio hacia los políticos, por cuanto muchos altos oficiales nigerianos fueron formados en academias británicas y educados en el autoritarismo y la represión; segundo, una autocracia estructural, es decir, una organización primordialmente jerárquica en donde los subordinados cumplen sin cuestionamiento alguno las órdenes de sus superiores; y tercero, mediocridad educacional, siendo tradicionalmente el ejército el destino de todos aquéllos que no tenían la oportunidad de desarrollar una actividad comercial o una profesión, por cuanto los ilustrados -ya sea por los bajos salarios o por el desprestigio de la carrera militar- optaban por otras alternativas (Ukpabi 1976).

La intervención de los militares nigerianos en política coincidió con el colapso del imperialismo británico y la búsqueda de la población local de una institución que consolidara una convivencia pacífica. Es producto de una perjudicial convergencia de factores de la más diversa índole que han debilitado el frágil Estado postcolonial: primero, el pluralismo cultural, el cual ha imposibilitado al gobierno federal inculcar en los ciudadanos un sentido de orgullo y lealtad a la nación que trascienden las diferencias étnicas; segundo, la inseguridad de la población, estando la historia de Nigeria plagada - por ejemplo- de masacres de ibos en la región norte del país; tercero, la inexistencia de valores comunes, tales como religión, lengua o cultura; cuarto, la inmovilidad social, derivada esta de una desilusión de la ciudadanía en relación a la actividad política luego de la independencia; y quinto, el fracaso del multipartidismo (Omoigui sin fecha)

El derrocamiento del Primer Ministro Abubakar Tafawa Balewa (1966) y, en especial, el estallido de la guerra civil (1967-1970), serán la génesis del pretorianismo en Nigeria. En efecto, tras el conflicto de Biafra se reafirma la auto-concepción mesiánica de los militares, por cuanto - primero- la guerra fue justificada en virtud de la necesidad de mantener la unidad de Nigeria, lo cual hizo al Gobierno Militar Federal más popular y fuerte; segundo, el discurso altruista mostrado durante la reconstrucción de los asentamientos tras el conflicto trajo nuevamente a la palestra la imagen de corrección de los soldados; y tercero, como resultado de la experiencia 
de la guerra, la seguridad nacional adquirió un significado especial que confirió a las fuerzas armadas la excusa para ejercer al máximo sus potencial coercitivo (Ayavi 2007, Gould 2013).

A partir de entonces, las relaciones cívico-militares en Nigeria se han deteriorado en consideración de limitadas transformaciones institucionales. En efecto, a juicio de Nwagwu (2002), las mayores dificultades para ello se fundan dos cuestiones esenciales: primero, el fracaso de una reforma y modernización de las fuerzas armadas, el cual responde en parte a las rivalidades étnicas que vive el país. Aun se mantiene el predominio de altos oficiales Hausa-Fulani al interior de los cuarteles, los cuales boicotean cualquier intento de profesionalización de las fuerzas armadas con la intención de mantener el statu quo y las prebendas asociadas a sus rangos.

Y segundo, la inmadurez de las elites, lo cual se ve en militares que no comprenden que en una democracia su rol se acota al mandato constitucional de proteger a la nación; como en los políticos, los cuales no internalizan que la subordinación de los militares al control civil no quiere decir que estos no sean ciudadanos y carezcan de derechos, o que no pueden hacer demandas al sistema político como cualquier otro grupo en la sociedad (Nwagwu 2002).

En suma, la estabilidad institucional de Nigeria no pasa por eliminar la autoridad civil o las fuerzas armadas, sino por el desarrollo de una cultura política que reconozca el valor de la responsabilidad en el ejercicio de los mandatos constitucionales. Sin ello, reflotarían las dictaduras militares, un factor que hoy traería consigo no solo la condena internacional y el colapso económico, sino también posiblemente una guerra civil y -en el peor escenario- la secesión territorial.

\section{FUNDAMENTOS DE UNA REFORMA DEL SECTOR DEFENSA: NOTAS PARA EL ANÁLISIS}

El concepto reforma del sector defensa es de naturaleza liberal y ha sido utilizado en la mayoría de los casos por los países occidentales en sus políticas de cooperación para el desarrollo. Su objetivo es fomentar transformaciones en este sector en los países receptores de ayuda internacional; o bien mejorar su rendimiento, especialmente, en escenarios de post conflicto ${ }^{4}$.

4 La difusión de las reformas del sector defensa se cuenta también dentro de la diplomacia militar, la cual considera el desarrollo de las siguientes actividades: contactos entre militares y autoridades civiles de alto rango del sector defensa; nombramiento de agregados militares en ciertas embajadas; 
Se pretende mejorar la gobernabilidad democrática, así como también la gestión eficiente y el control de las instituciones de la seguridad nacional. El origen de estos programas se remonta a la Guerra Fría, cuando las políticas de cooperación de las potencias internacionales no estaban destinadas a promover el fortalecimiento de la democracia, sino a fomentar relaciones estratégicas con aliados clave, particularmente, con dictaduras militares o regímenes autoritarios que simplemente había derrumbado los pilares del Estado de Derecho (Carreño y Martínez 2016, Ball 2010).

Tras la caída de la Unión Soviética en 1991, las prioridades estratégicas de las potencias occidentales debían ajustarse a los nuevos tiempos. El objetivo pasó a ser impulsar la liberalización de los países de Europa Oriental, para lo cual debía establecerse en ellos un marco institucional que permitiese vincular los temas de seguridad -primero- al desarrollo político y económico; segundo, a una reforma del sector público; y tercero, a un cambio en la cultura política de los gobernantes (Cottey y Forster 2004). Así, por ejemplo, se alentó la adhesión a los principios democráticos que orientan las relaciones cívico-militares como condición previa para ingresar a la Unión Europea y otras organizaciones internacionales.

Desde un punto de vista doctrinario, las reformas del sector defensa estuvieron influenciadas por el discurso de muchos políticos e intelectuales que abogaban por ampliar el alcance del concepto de seguridad, en particular, por incorporar la lógica de la seguridad humana (United Nations Trust Fund for Human Security 2009: 8-9). En este contexto, la protección de las personas es una cuestión crítica a nivel nacional e internacional, por lo tanto, la seguridad requerida por los ciudadanos no se limita a la defensa o mantenimiento del orden público, sino también exige incorporar dimensiones políticas, económicas y sociales más amplias.

Luego de instalarse en la agenda internacional este debate, los actores más importantes del mundo no occidental alzaron sus voces y buscaron influir en la discusión. Destaca en este proceso la experiencia de Sudáfrica, la cual durante la década de los noventa transformó completamente su Defensa Nacional y derogó todas aquellas disposiciones legales que mantenían la

suscripción de acuerdos de cooperación; formación de militares extranjeros; asesoramiento en el control democrático de las fuerzas armadas, gestión de la defensa y otras áreas técnicas propias del ámbito militar; visitas de buques extranjeros; colocación de personal militar o civil en los ministerios de defensa de los países socios o en sus fuerzas armadas; despliegue de equipos de formación; suministro de material militar; ejercicios militares combinados; entre otras (Cheyre 2013). 
institucionalidad de Apartheid dentro de las fuerzas armadas (Cawthra 1997).

En términosgenerales, la reforma del sector defensa como condicionalidad a la cooperación internacional fue impulsada principalmente por el Departamento de Desarrollo Internacional del Reino Unido (DFID en su sigla en inglés). Este organismo, junto al Comité de Ayuda al Desarrollo de la Organización para la Cooperación y el Desarrollo Económico (DAC en su sigla en inglés), estableció un conjunto de exigencias en este campo a los estados receptores, las cuales consideraban el control civil de los militares, la modernización del pensamiento estratégico y reformas al Poder Judicial.

En 2004, los miembros del DAC acordaron un documento orientativo en esta materia, el cual definió la reforma del sector defensa como "(...) la transformación del 'sistema de seguridad' -el cual incluye todos los actores, sus roles, responsabilidades y acciones- que trabajan juntos para administrar y operar el sistema de una manera que es más consistente con las normas democráticas y sólidos principios de buen gobierno" (OECD 2005: 20).

De acuerdo al CAD, el objetivo de una reforma del sector defensa es

[...] aumentar la capacidad de los países socios para satisfacer toda la gama de necesidades de seguridad dentro de sus sociedades de una manera consistente con las normas democráticas y los sólidos principios del buen gobierno, la transparencia y el Estado de Derecho (OECD 2005: 3).

Se incluye también, pero de manera subsidiaria, la asistencia más tradicional en materia de defensa, inteligencia y fuerzas policiales.

Así, en lo práctico, el enfoque defendido por el CAD está lejos de ser comprehensivo, por cuanto ha acotado los problemas de la defensa nacional solo a tres cuestiones: primero, el suministro ineficaz e ineficiente de seguridad; segundo, inadecuados mecanismos de rendición de cuentas y supervisión de las instituciones de la defensa nacional; y tercero, indebida prestación de justicia y seguridad a todos quienes viven dentro del Estado (Ball 2010: 36).

En este contexto, los "países socios" o "receptores" se han mostrado más bien escépticos frente a las políticas de reforma del sector defensa. Hay varias razones para esto. En primer lugar, los países occidentales que proveen asistencia en materia de seguridad y defensa continúan prefiriendo 
un enfoque clásico, es decir, programas de entrenamiento militar y transferencia de sistemas de armas. Se obvia, así, la implementación de planes que favorezcan el desarrollo de una nueva cultura organizacional en las instituciones de la defensa nacional, así como el fortalecimiento de los mecanismos de control democrático de las fuerzas armadas. Ejemplos de esta mala práctica son los programas estadounidense desplegados en Liberia (2005) y Chad (2007) (Ball 2010: 37).

En segundolugar, existen muchas visiones (yvarias deellas contradictorias) en torno a un tema esencial: “¿qué seguridad está en juego?”. Desde la perspectiva de los donantes, la prioridad está en atender en los países receptores las necesidades de seguridad y justicia de sus ciudadanos; como también en mejorar los sistemas de inteligencia y contraterrorismo, lo cual generalmente responde a sus propios intereses y no a los declarados por los actores locales. Asimismo, los donantes suelen mostrarse reticentes a apoyar reformas en el sector militar.

Desde la perspectiva de los países receptores, la discusión de la reforma del sector defensa suele darse solo entre la elite política y/o militar y los estados donantes; obviándose así los principios de transparencia, rendición de cuentas e inclusión. En el caso de África, es difícil comprender la marginación de la sociedad civil en la discusión de estos temas, por cuanto los africanos han abrazado en la mayoría de los casos visiones comprehensivas de la seguridad; como también impulsado una serie de iniciativas con miras a entrar en estos debates políticos. Destacan entre estas la Red Africana del Sector de la Seguridad, la Iniciativa de Reforma Árabe y la Red para la Gestión de la Defensa y la Seguridad Sudafricanas (Van Nieuwkerk 2014).

Al respecto, Sedra (2010) sostiene que el debate en torno al alcance de las reformas del sector defensa guarda relación con diferentes valoraciones de la lógica estatista y occidental del concepto de seguridad. Los más ortodoxos estiman que los problemas que enfrentan estas reformas responden a la incapacidad o falta de voluntad de los donantes para defender los principios del modelo, es decir, una visión que ve en el Estado el único actor capaz de satisfacer las necesidades de seguridad de personas. Así, en este escenario, las políticas deberían centrarse en ampliar la capacidad de actuación de las instituciones estatales, como también en replantear su relación con la sociedad en general.

Por el contrario, los miembros de la escuela posliberal rechazan este enfoque, por cuanto -a su juicio- el actual modelo de reforma del sector defensa se orienta principalmente los intereses los actores externos y no a las 
necesidades de los receptores de la reforma. Abogan por transformaciones que nazcan de procesos decisorios más flexibles y participativos, en donde se refleje la amplia variedad de contextos, actores y amenazas a fin de maximizar la utilización de los recursos disponibles

Naciones Unidas, por su parte, también ha destacado la importancia de las reformas del sector defensa. En efecto, en 2008 el Secretario General Ban Ki-moon publicó un detallado informe que destaca el rol de la organización en esta materia, en especial, en la consecución de objetivos en áreas críticas coincidentes en varios de procesos similares. Estas áreas son: provisión de un cuerpo constitucional que legitime y controle el uso de la fuerza de acuerdo a estándares universalmente aceptados en materia de derechos humanos; institucionalización de mecanismos de gestión política de las instituciones responsables de la seguridad nacional; provisión de capacidades, estructuras, personal, equipamiento y recursos idóneos para garantizar la seguridad; establecimiento de mecanismos de coordinación entre los diversos actores políticos y militares; e inculcación de una cultura de servicio, es decir, la promoción de los siguientes principios entre todos quienes conforman el sector defensa: unidad, integridad, disciplina, imparcialidad y respeto de los derechos humanos en el cumplimiento de los deberes (UN/Secretary-General 2008: 6).

En el caso de África, la crisis del Estado postcolonial determina la inseguridad que se vive en muchos rincones del continente. En efecto, la ingobernabilidad se manifiesta en la naturaleza y funcionamiento de las instituciones estatales, es decir, en cómo se concibe su papel dentro de la sociedad. Así, en este contexto, los principales argumentos para concretar una reforma del sector defensa son superar el legado de conflictos violentos y regímenes autoritarios y transformar al Estado en un vehículo que permita alcanzar la paz, la seguridad y el desarrollo.

\section{HACIA UNA REFORMA DEL SECTOR DEFENSA EN NIGERIA}

Tras la muerte de Sani Abacha, el 8 de junio de 1998, asumió la conducción del gobierno el General Abdulsalami Abubakar, quien entre junio de 1998 y abril de 1999 logró sentar las nuevas bases del sistema político de Nigeria. La elección misma de Abubakar como Jefe de Estado Interino por parte del Consejo de Gobierno Provisional, máximo órgano político a través del cual actuaban los militares, representó una clara derrota de los leales al fallecido dictador.

La mala gestión económica, la corrupción y la violación masiva de los derechos humanos hundieron a Nigeria en la decadencia (Abegunrin 
2003). En paralelo, los Estados Unidos, Gran Bretaña y otras potencias occidentales exigieron la democratización del país como condición previa para acceder a la asistencia económica y financiera externa que tanto requerían para enfrentar la grave crisis social. En respuesta a estas expectativas nacionales e internacionales, Abubakar trazó como objetivo conducir una transición política que permitiera en un plazo no mayor a diez meses entregar el poder a un gobernante democráticamente electo.

Durante todo ese período, Abubakar debió enfrentar la presión de un sector importante de las fuerzas armadas que exigía retrasar la entrega del poder hasta 2000. El líder nigeriano se negó y decidió impulsar las primeras reformas estructurales dirigidas a reorganizar las instituciones militares. Sabiendo lo difícil que era llevar a cabo esta tarea, Abubakar apeló al apaciguamiento como estrategia a fin de garantizar el éxito de la transición política y asegurar así el concurso de los oficiales menos radicalizados (Campbell 2006).

Tras disolver el Gabinete Federal y nombrar a hombres de su confianza, inició una gira por todos los cuarteles explicando por qué era un "imperativo para los militares volver a su función constitucional de defender la integridad territorial del país" (Manea y Rüland 2013: 61); instándolos -además- públicamente en varias ocasiones a no volver a secuestrar el proceso político, ya que las fuerzas armadas deben someterse a un gobierno elegido democráticamente y jugar los roles asignados por ellos.

En la línea del apaciguamiento, a finales de 1998 el gobierno de Abubakar aumentó el salario a los soldados y oficiales, como también decidió la creación de un comité especial para analizar las funciones específicas de las fuerzas armadas y la policía en el marco de un orden democrático (Olonisakin 1999). Las reuniones de este comité se celebraron en Abuja y en las mayores zonas geopolíticas del país (Southwest Region, Southeast Region, South-South Region, Northeast Region, Northwest Region, North-Central Region), fijándose como temas centrales de discusión el bienestar de los militares, el diseño de una nueva política salarial, la profesionalización de la actividad y el compromiso de las fuerzas armadas con la democracia y sus instituciones. Estos esfuerzos claramente ayudaron a cimentar la transición política, sin embargo, constituyeron solo un ejercicio de autoevaluación de los militares en el cual no tuvieron cabida ni los dirigentes civiles ni la sociedad civil.

Más allá de esto, el gobierno logró abolir varias restricciones y prácticas antidemocráticas, lo cual ayudó a descomprimir considerablemente el clima social. El 20 de julio de 1998, Abubakar desestimó por completo 
la agenda de Abacha y fijó sin demora un nuevo calendario político que consideraba la celebración de elecciones presidenciales y parlamentarias en febrero de 1999 y la inauguración de la Cuarta República el 29 de mayo del mismo año. Disolvió, además, los partidos políticos constituidos durante la dictadura, como también determinó la prohibición a los militares de financiar en el futuro cualquier actividad política con miras a frenar su intervención en estos asuntos (Campbell 2006).

Se ordenó la inmediata liberación de los presos políticos, en particular, de altos dirigentes pertenecientes a agrupaciones como la Oposición Democrática Nacional, la Organización de Libertades Civiles y la Asociación de Abogados de Nigeria (Olonisakin 1999). Abubakar se comprometió también a ordenar una exhaustiva investigación de las denuncias de tortura y violación de los derechos humanos por parte de los seguidores de Abacha. Poco antes de dejar el cargo, el líder nigeriano derogó el Decreto N. ${ }^{\circ} 2 / 1984$ de Seguridad del Estado, el cual permitía la detención arbitraria de cualquier persona, arguyendo la evidente ilegalidad de esta normativa a la luz de la recién promulgada Constitución Política (Manea y Rüland 2013).

La redacción de esta última fue muy controvertida. Se denunció la poca transparencia del proceso, así como la ausencia de instancias de participación ciudadana (Nwankwo 2003, Olonisakin 1999). En efecto, solo algunos militares moderados, más un pequeńo grupo de juristas liderados por el abogado Nikki Tobi, fueron los encargados de organizar las consultas públicas en todo el país, para más tarde abocarse a redactar la nueva carta magna.

La vocación democrática de Abubakar quedó en entredicho tras este proceso, y más aún luego de la rápida aprobación del texto constitucional definitivo a través de un mero decreto (Ibeanu y Egwu 2007, Ugoh 2005). A pesar de estas críticas, la dictación de la Constitución Política de 1999 significó un importante avance institucional, por cuanto se logró restaurar el control civil de las Fuerzas Armadas. Estas quedaron bajo la supervisión de la Asamblea Nacional, como también bajo el mando directo del Presidente de República en su calidad de Comandante en Jefe (Nwolise 2002).

De cara a las elecciones de febrero de 1999, y a fin de salvaguardar la transparencia del proceso electoral, se aconsejó a los oficiales militares activos y en retiro no involucrarse en la carrera presidencial. Al respecto, destaca la actuación del General (r) Tunde Idiagbon, antiguo Jefe del Estado Mayor, quien hizo hincapié en la necesidad de que los militares 
dieran señales inequívocas de su retorno a los cuarteles (Manea y Rüland 2013). Abubakar, por su parte, defendió el derecho de los uniformados a albergar ambiciones políticas, sin embargo, recordó a estos que su deber no es gobernar, por lo cual, debían presentar inmediatamente la renuncia a sus cargos militares, unirse a un partido político y concurrir como cualquier ciudadano a los próximos comicios.

La elección de Obasanjo dio garantías de estabilidad a amplios sectores de la sociedad nigeriana. En efecto, su vocación democrática, su oposición a la dictadura de Abacha, su prestigio internacional y su condición de héroe de guerra, permitieron alinear tras él a muchos civiles y militares (Akinrinade 2006, Ihonvbere y Shaw 1998). Asimismo, el hecho de ser un Yoruba alivió la tensión que aún existía tras la anulación de las elecciones presidenciales de 1993 y en donde había ganado otro representante de aquella etnia: Moshood Abiola.

Al asumir el poder en mayo de 1999, Obasanjo insistió en la necesidad de establecer una fuerte institucionalidad que impidiera una nueva injerencia de los militares en la vida política. La nueva doctrina estima que el profesionalismo se desarrolla mejor en un régimen democrático, por cuanto en una dictadura los militares son vistos como enemigos por la sociedad. Asimismo, debido a que son el instrumento más creíble de violencia organizada, los autócratas se sienten incómodos con ellos, por lo cual harán todo lo posible por debilitarlos (Shiyanbade 2000).

En este contexto, la discusión pasó, entonces, por determinar cuál modelo era el más idóneo para la conducción de relaciones cívico-militares en Nigeria en consideración de su cultura política y su cultura estratégica 5 . Las alternativas consideradas fueron las siguientes: la diarquía cívicomilitar, el modelo socialista, el militarismo desarrollista y el modelo liberal occidental (Elaigwu 2013).

Nigeria, finalmente, escogió este último, el cual ha estado inherentemente presente en la conducción de la defensa nacional desde la independencia en 1960. En concreto, las fuerzas armadas se encuentran preparadas -en principio- para defender la integridad del Estado y su soberanía contra

5 La cultura estratégica se refiere a un conjunto de creencias, supuestos y modos de comportamiento derivados de experiencias comunes y narrativas orales y escritas aceptadas por la nación, los cuales constituyen - primero- la identidad colectiva; segundo, estructuran las relaciones con otros Estados; y tercero, determinan los fines y medios adecuados para la consecución de los objetivos vinculados a la inserción internacional y la seguridad nacional (Johnston 1995). 
agresores externos, pero no contra los propios ciudadanos. Del mismo modo, no intervienen en las estructuras y procesos políticos de orden interno. Así, finalmente, los militares son depositarios de los medios de fuerza, los cuales se encuentran monopolizados por el Estado; quien a través de sus instituciones democráticas organiza y controla estrictamente su uso en consideración del bien común.

En este sentido, si bien la Constitución Política de 1999 define claramente cuáles son las funciones de las Fuerzas Armadas de Nigeria ${ }^{6}$, las prolongadas dictaduras pretorianas han hecho que los militares se sientan cómodos en el ejercicio del poder político. Es más, un sector importarte de ellos estima que el resentimiento y hostilidad hacia su presencia es solo una moda pasajera y que los gobiernos civiles no son más que un paréntesis en su misión de conducir los destinos del país (Carreño 2016).

Durante los primeros meses de gobierno se habló de una importante profesionalización de las fuerzas armadas, como también de un estricto control de su actuación por parte de los diferentes Poderes del Estado. En este sentido, el Presidente de la República recuperó facultades inherentes a su cargo en un orden democrático, destacando entre estas la atribución exclusiva para determinar el uso operacional de la fuerza; nombrar a los Jefes de Estado Mayor del Ejército, la Armada y la Fuerza Aérea; conformar los Altos Mandos de cada rama de las fuerzas armadas; y presidir el Consejo de Defensa Nacional y el Consejo de Seguridad Nacional.

La Asamblea Nacional, por su parte, reivindicó para sí el ejercicio de tres importantes facultades en el ámbito de la defensa nacional. Primero, legislar para regular los poderes del Presidente de la República como Comandante en Jefe, como también para determinar el reclutamiento, ascenso y control disciplinario de todos los militares ${ }^{7}$. Segundo, el Poder Legislativo ejerce el

6 Estas funciones son: la defensa de Nigeria ante una agresión externa; el mantenimiento de su integridad territorial y la seguridad de sus fronteras frente a violaciones terrestres, marítimas y aéreas; actuar como asesores de las autoridades civiles en el mantenimiento del orden público y la seguridad interior como prescribe la Asamblea Nacional; y cumplir con todas las demás funciones que puedan ser mandatadas por la Asamblea Nacional.

7 La Asamblea Nacional puede legislar también para resguardar el carácter federal de las Fuerzas Armadas de Nigeria. Se trata de un principio vigente en los ordenamientos constitucionales desde 1979 y cuyo objetivo es garantizar que los nombramientos en las instituciones públicas reflejen claramente la diversidad lingüística, étnica, religiosa y geográfica del país. La aplicación de este principio en la administración pública federal y en los militares ha supuesto un gran problema: equilibrar el 
control de las Fuerzas Armadas de Nigeria a través del Senado y la Cámara de Representantes y sus Comisiones Permanentes de Defensa y los comités específicos de cada rama, las cuales pueden exigir la comparecencia de cualquier alto responsable militar. Por último, la Asamblea Nacional tiene la facultad constitucional de autorizar las asignaciones presupuestarias, pudiendo invitar -incluso- a la discusión parlamentaria a miembros del Alto Mando Militar a objeto conocer su opinión técnica en consideración de los requerimientos del Ejecutivo.

Obasanjo cimentó la reforma del sector defensa en cinco principios enunciados el 24 de julio de 1999 en la Academia de Guerra de Nigeria: primero, la aceptación del Presidente de la República como Comandante en Jefe de las Fuerzas Armadas y la supremacía de los funcionarios electos sobre los funcionarios designados en todos los niveles; segundo, la aceptación de la supremacía civil del Ministerio de Defensa y otras instituciones políticas; tercero, las decisiones con respecto a las operaciones militares y su materialización deben servir a los objetivos establecidos por la autoridad civil; cuarto, la aplicación de preceptos de jurisdicción civil en todas las investigaciones y juicios militares; y quinto, la competencia del Poder Judicial para revisar las acciones o decisiones tomadas por los funcionarios judiciales militares (Fayemi y Olonisakin 2008).

Dada la evidente fragilidad de la democracia nigeriana, Obasanjo debió privilegiar su primer mandato (1999-2003) el alcance de los tres primeros objetivos, por cuanto los restantes implicaban abordar también el tema de la corrupción en el Poder Judicial. Durante la discusión de estas cuestiones, el gobierno -sin embargo- mostró su incapacidad para negociar con la Asamblea Nacional la aprobación de reformas dirigidas a eliminar los enclaves autoritarios aún vigentes en la legislación militar. Asimismo, tampoco logró impulsar el control democrático de las fuerzas armadas por parte de los medios de comunicación y la sociedad civil; ni desarrollar una comunidad epistémica en torno a los estudios de seguridad y defensa (Adejumobi 2010).

Frente a las duras críticas a su inmovilismo político los primeros meses de gobierno, Obasanjo -ante la sorpresa de todos- ordenó la desvinculación de las Fuerzas Armadas de Nigeria de noventa y tres oficiales militares de alto rango. Se contaban entre ellos, incluso, varios generales de Ejército (26), almirantes (11) y generales de la Fuerza Aérea (12) (Manea y Rüland 2013). Todos estos fueron considerados "agentes políticos", ya que habían

mérito y el sistema de cuotas al momento de determinar las diferentes promociones (Adamolekun, Erero y Oshionebo 1991) 
servido durante las pasadas dictaduras (1985-1999) como ministros de estado, gobernadores y delegados militares.

Esta purga buscó despolitizar e impulsar una verdadera profesionalización de las fuerzas armadas. En esta dirección, Obasanjo ignoró el consejo de algunos asesores que recomendaban no incomodar a los militares y decidió reorganizar los Estados Mayores en el Ejército, la Armada y Fuerza Aérea. Estos nuevos altos oficiales, en su amplia mayoría, pertenecían a grupos étnicos minoritarios de las regiones centrales del país; rompiéndose así la perniciosa tradición de hegemonía de los Hausa-Fulani en las fuerzas armadas (Bassey 2011).

Aunque Obasanjo confió el Ministerio de Defensa Nacional a un antiguo General de Ejército, Theophilus Danjuma, cimentó las bases para una completa modernización de esta cartera, en especial, para restablecer el control político de los militares. Durante su mandato, todos los responsables de este ministerio fueron civiles, destacando incluso el nombramiento de la primera mujer en este alto cargo: Modupe Adelaja. Asimismo, durante la gestión de Danjuma se intentó implementar una de las reformas más polémicas: la reducción del número de efectivos de las fuerzas armadas de 80.000 a 50.000 efectivos (Sanusi 2011) ${ }^{8}$. La fuerte resistencia de oficiales y soldados de tropa a esta iniciativa obligó al ministro a abandonar su plan original y retrasar la implementación de esta medida con miras a un fin mayor: mantener el orden institucional.

Otra importante decisión en el marco de la reforma del sector defensa fue el establecimiento en junio de 1999 de la "Comisión de Investigación de Violaciones de Derechos Humanos"9. Esta estuvo encabezada por el

8 Actualmente, las Fuerzas Armadas de Nigeria la integran 80.000 efectivos, los cuales se encuentran distribuidos de la siguiente manera: Ejército, 62.000; Armada, 8.000; Fuerza Aérea, 10.000 (IISS 2016) Se consideran también dentro del sector defensa la fuerza policial, los cuerpos paramilitares (por ejemplo, servicio de inmigración, servicios de inteligencia), el Poder Judicial, el Ministerio de Justicia, los servicios correccionales, los equipos de seguridad privada, las milicias (por ejemplo, Odua People's Congress, Bakassi Boys, Hizba Corps) y los grupos de vigilancia comunitaria (Fayemi y Olonisakin 2008: 245)

9 No obstante los obstáculos, es meritorio el trabajo de esta comisión, especialmente, si se considera que contó para su funcionamiento solo con US\$ 450.000 que fueron donados por la Fundación Ford. Asimismo, la asistencia técnica a los integrantes de esta pasó por el esfuerzo de solo doce funcionarios de otras reparticiones públicas. La Comisión Oputa, tras evaluar algunos antecedentes, solicitó -además- la colaboración del Inspector General de la Policía, en específico, la creación de una 
juez Chukwudifu Oputa y su principal objetivo fue determinar las causas, naturaleza y extensión de los graves atropellos de agentes del Estado acaecido en Nigeria entre el 15 de enero de 1966 y el 28 de mayo de 1999 (Manea y Rüland 2013). Esta instancia no solo se creó para disuadir la potencial oposición de los ex dictadores militares, sino también para develar ante los nigerianos los excesos de distintos regímenes autoritarios e inculcar así en ellos el valor de la democracia.

Durante los tres años de investigación, la Comisión Oputa ganó el reconocimiento de un amplio sector de la población local y la comunidad internacional. Se examinaron más de 10.000 denuncias, se escuchó el testimonio de 2.000 testigos y se recibieron 1.750 pruebas. Tras todo ello, se elevó al gobierno un informe final de 15.000 páginas organizadas en ocho volúmenes (Manea y Rüland 2013, Falana 2010).

Como era predecible, las conclusiones de la Comisión Oputa enardecieron a la oposición, la cual propició focos de violencia étnica en muchas partes del país. Antiguos dictadores como Ibrahim Babangida, Muhammadu Buhari e, incluso, Abdulsalami Abubakar se negaron a testificar ante esta instancia, arguyendo como excusa la inconstitucionalidad de su actuación. La Corte Suprema de Nigeria reconoció, finalmente, esta alegación y procedió a avalar la no comparecencia de los ex gobernantes (Hayner 2008). Así, entonces, el gobierno de Obasanjo -amenazado por la sedición-optó por no difundir los resultados de las investigaciones, lo cual impidió denunciar a los responsables de los crímenes.

Más allá de su simbolismo, la actuación de la Comisión Oputa era limitada por cuanto carecía de facultades jurisdiccionales, las cuales recaían únicamente en el Poder Judicial. Obasanjo se había inspirado en una comisión similar que trató con éxito las cuestiones de derechos humanos en Sudáfrica, sin embargo, existía una gran diferencia: la comisión constituida por Nelson Mandela tenía un mandato claro derivado de acuerdos legislativos; mientras que la iniciativa nigeriana nunca fue discutida en la Asamblea Nacional, la cual tampoco nunca mostró mayor interés en abordar este tema.

Menos ambigüedad en su actuar mostró el sistema de justicia militar. Los crímenes cometidos por miembros de las Fuerzas Armadas de Nigeria serían juzgados por tribunales civiles; mientras que las decisiones de las cortes marciales estarían sujetas a revisión de la Corte Suprema. Sin

unidad especializada para investigar treinta y cinco casos en los que las pruebas sugerían que la acción legal era viable (Hayner 2008). 
embargo, un número importante de militares activos y en retiro presentó ante la Asamblea Nacional varias quejas por desvinculaciones injustificadas y/o no pago de pensiones, lo cual develó las profundas deficiencias de funcionamiento de todas las instancias jurisdiccionales nigerianas (Falana 2010). En el ámbito político, esta situación también se transformó en una amenaza, por cuanto el despido de miles de soldados sin derecho a un debido proceso era una fuente de tensión que podía ser fácilmente aprovechada por los golpistas.

El gobierno de Obasanjo consideró también dentro de la reforma del sector defensa la contratación de Military Professional Resources Initiative (MPRI), una empresa consultora estadounidense especializada en asuntos estratégicos (International Institute for Democracy and Electoral Assistance 2000). Esta fue la encargada de preparar un plan para instaurar el control civil de los militares nigerianos, proporcionar asistencia técnica y entrenar a los soldados que participarían próximamente en misiones de paz bajo el mandato de la Unión Africana o Naciones Unidas (Fayemi 2005, Garba 2008).

La misión encomendada a MPRI fue patrocinada por la United States Agency for International Development (USAID) y el Pentágono, lo cual fue muy cuestionado por los militares más nacionalistas. Destaca entre estos el General de Ejército Victor Malu, quien decidió jubilar anticipadamente a raíz de la imposición de estas políticas por parte las potencias internacionales (Fayemi y Olonisakin 2008, Yoroms 2005). La contratación de esta empresa consultora respondió más que nada a los esfuerzos nigerianos de congraciarse diplomáticamente con Occidente, por cuanto -en términos concretos- su actuación tuvo un impacto muy reducido en las transformaciones militares que ha vivido Nigeria durante la Cuarta República.

Por otra parte, en consideración de las críticas al proceso de redacción y aprobación del texto constitucional, Obasanjo convocó al Poder Legislativo a debatir prontamente todas aquellas cuestiones que ameritaban una enmienda. Para el Ejecutivo nigeriano el control efectivo de las fuerzas armadas por parte del Presidente de la República era un tema urgente, sin embargo, este recibió muy poca atención en la Asamblea Nacional (Fayemi 2002: 227, Nwankwo 2003: 95).

En junio de 1999, el Center for Democracy and Development (CDD), un foro de la sociedad civil nigeriana, organizó un seminario de alto nivel titulado Constitución y Futuro de la Democracia en Nigeria. En este marco, se impulsó la formación del Foro Ciudadano para la Reforma 
Constitucional, el cual participó activamente en el debate de las enmiendas junto a la Comisión de Expertos nombrada por Obasanjo y que presidía el connotado político Clement Ebri (Abia 2008: 172). La Asamblea Nacional fue la última en sumarse y solo en 2001 constituyó un Comité Bicameral ad hoc para tratar estos temas.

La Comisión Ebri propuso incorporar una disposición que permitía castigar a los golpistas con carácter retroactivo, por cuanto si bien la Constitución Política prohíbe la sedición en el artículo 1 (2), no prevé sanciones para ese delito (Abia 2008). Se estimó también necesario considerar los intentos de golpe de Estado un "acto de traición", por lo cual, todos los nigerianos estarían facultados para repelerlos. A pesar del apoyo de varios congresistas y la opinión pública, este artículo fue rechazado finalmente- en la discusión parlamentaria, por cuanto la Asamblea Nacional se negó a incorporar también una cláusula constitucional que permitía un tercer mandato de Obasanjo (Suberu 2010).

Finalmente, en cuanto al marco legal específico que regula la actuación de las fuerzas armadas, la discusión en la Asamblea Nacional se remitió a cuatro proyectos de ley que emanaron en 1999 de un comité especial constituido por Ghali Umar Na’Abba, entonces Presidente de la Cámara de Representantes. Los proyectos legislativos en cuestión fueron: Ley sobre Fuerza de Reserva, Modificaciones a la Ley de la Agencia Nacional de Gestión de Emergencias, Ley de Infraestructura Mínima para Servicios de Seguridad y Ley sobre el Rol Secundario de las Fuerzas Armadas en el Desarrollo Nacional.

Estas propuestas buscaban legalizar la participación de los militares en algunas tareas gubernamentales, como también en el sector privado. En efecto, inspirados en la teoría de modernización, se planteó la idea de aprovechar las capacidades profesionales de las fuerzas armadas en beneficio de la sociedad; lo cual también acrecentaría la dignidad de sus funciones y reduciría el riesgo a una intromisión en cuestiones políticas. Este planteamiento, como sostiene Elaigwu (1997), se condice con las tradiciones africanas, sin embargo, colisiona con los paradigmas que orientan las relaciones cívico-militares en el mundo occidental.

$\mathrm{Al}$ igual que muchas otras reformas, estas iniciativas legislativas tuvieron un mero simbolismo, por cuanto no modificaron sustantivamente el marco jurídico de los militares nigerianos. Así, por ejemplo, el Acta de las Fuerzas Armadas de Nigeria, un decreto aprobado en 1993 por el gobierno de facto, fue promulgado como ley por la Asamblea Nacional sin siquiera discutirse su revisión o derogación (Elaigwu 2013). Solo en 2009 el Poder 
Legislativo planteó estudiar la primera gran modificación a esta normativa: autorizar al Presidente de la República a desplegar tropas con el fin de reprimir disturbios civiles, pero siempre bajo la estricta supervisión de la Cámara de Representantes y el Senado.

\section{LAS (NUEVAS) FUERZAS ARMADAS DE NIGERIA: PENSAMIENTO ESTRATÉGICO Y POLÍTICA EXTERIOR}

La necesidad de mantener una capacidad militar con fines estrictamente internos no permitió la modernización y equipamiento de las Fuerzas Armadas de Nigeria hasta la guerra civil. En efecto, por entonces se concretó un replanteamiento general de los fundamentos doctrinarios y estratégicos, como también del proceso de formulación, implementación y evaluación de la política de defensa (Carreño 2016).

Sin embargo, aun cuando la política exterior nigeriana adoptó un carácter más proactivo tras el conflicto de Biafra, no será hasta la Cuarta República que se evidencie una mayor sinergia entre seguridad nacional, política de defensa y diplomacia. En efecto, África Occidental, al igual que el resto del continente, vivió un proceso de descolonización que colmó de esperanzas a una población local marcada por la desdicha de la esclavitud; la opresión política, social y cultural; y el despojo de sus recursos naturales a manos del colonizador europeo. Sin embargo, los años venideros no fueron más alentadores, por cuanto la imposibilidad de consolidar las instituciones estatales, la consecuente instrumentalización de estas por parte de una elite y las dificultades para romper con el esquema de dependencia de las exmetrópolis, han llevado a una persistencia de los conflictos internos y a un empeoramiento de las condiciones de vida (Carreño 2016).

Así, en consideración de estas experiencias, el gobierno nigeriano comprendió que su propia supervivencia y prosperidad depende, en gran medida, de la colaboración militar que puedan prestar en la resolución de algunos conflictos africanos, en especial de aquellos que podrían impactar directamente en su seguridad nacional. Para el régimen de Abuja es importante también que sus fuerzas armadas participen en operaciones de paz $^{10}$, por cuanto permite a estas sumar experiencia en trabajos conjuntos y combinados con militares extranjeros, como también elevar el estatus diplomático y estratégico de Nigeria a nivel regional.

10 En estos momentos hay tropas nigerianas desplegadas en misiones de paz en Costa de Marfil, República Democrática del Congo, Guinea-Bissau, Líbano, Liberia, Malí, Sudán, Sudán del Sur y Sahara Occidental (IISS 2016) . 


\section{EjÉrCito DE Nigeria}

Aunque históricamente el Ejército ha sobrevivido a períodos de cuestionamiento a su profesionalismo, sobre todo tras la caída de la Primera República, la situación enfrentada a inicios de la Cuarta República era aún más complicada a raíz de las nuevas exigencias de la comunidad internacional (Dokubo 2011). La globalización, la interdependencia económica y cambios sociales experimentados tras la Guerra Fría influyeron de manera dramática en su legitimidad y capacidad.

Sin embargo, un factor clave en la reconstrucción del Ejército de Nigeria tras la democratización fue la revalidación de su estatus como una profesión fundamental en la sociedad. En efecto, esto supuso profesionalizar la actividad e incentivar la discusión permanente sobre temas estratégicos y doctrinales entre los oficiales. Los nuevos retos que enfrentan los militares exigen al Alto Mando entender e identificar su importante papel en el desarrollo de habilidades colectivas que impulsan la constitución de un ejército entrenado.

Por último, enfatizándose su carácter profesional, el Ejército de Nigeria debió renovar su identidad, lo cual -a su vez- permitió a sus miembros alinear los intereses personales e institucionales. Esta alineación entre individuos e identidad de la profesión es fundamental para la viabilidad de las fuerzas armadas en largo plazo, ya que el profesionalismo reside en última instancia en el conocimiento experto, el carácter y la motivación personal.

\section{Armada De Nigeria}

Como se sostiene en la Constitución Política de 1999 y en el Acta N. ${ }^{\circ} 20$ de la Asamblea Nacional, la Armada de Nigeria tiene por funciones: primero, la defensa del país; segundo, hacer cumplir y ayudar a coordinar la aplicación de toda la legislación concerniente a materias aduanera, anti-piratería, pesca ilegal e inmigración; tercero, hacer cumplir y ayudar a coordinar la aplicación de las normas marítimas nacionales o internacionales; y cuarto, promover, coordinar y hacer cumplir las normas de seguridad en las aguas territoriales y la zona económica exclusiva.

En virtud de lo anterior, es evidente que el mandato legal de la Armada es predominantemente policial, sin embargo, en el contexto de la experiencia de la guerra civil y las crisis en Liberia y Sierra Leona, se ha hecho necesario desarrollar un poder naval efectivo; más aún en consideración del compromiso diplomático y militar del país con la paz y seguridad 
regionales. En este sentido, la estrategia Tridente formulada en 1988 fue el marco de sus operaciones navales, destacando entre sus objetivos la defensa costera, el control del mar y el apoyo a las tareas del ejército por medio del transporte marítimo y el fuego naval (Ibrahim 2011).

Sin embargo, las amenazas suscitadas dentro de sus aguas interiores, la zona económica exclusiva y el Golfo de Guinea, llevaron a Nigeria a una reinterpretación estratégica. Actualmente, más del $80 \%$ de los ingresos nigerianos provienen de la explotación de hidrocarburos, la mayoría de los cuales son extraídos en el continente y aguas afuera. Del mismo modo, la mayor parte de las actividades de importación y exportación son llevadas a cabo a través de distintos puertos.

Esta situación ha implicado crecientes amenazas a la seguridad del régimen de Abuja: primero, ataques de grupos armados contra instalaciones petrolíferas en el delta del Níger; segundo, toma de rehenes y/o secuestros de extranjeros; tercero, robo de crudo de petróleo y sus derivados; cuarto, aumento de la piratería, lo cual ha hecho de las rutas marítimas nigerianas las más peligrosas de África junto a las de Somalia; quinto, caza furtiva de recursos pesqueros por parte de buques procedentes de Asia, Europa y otras partes de África; y sexto, degradación medioambiental (Ibrahim 2011).

Estas vulnerabilidades derivan esencialmente de las actuales deficiencias de la Armada de Nigeria, en especial, en materia de capacidad y funcionamiento de sus flotas. Esta situación puede atribuirse a la ausencia de una eficaz y eficiente estrategia marítima nacional que establezca las prioridades de equipamiento, así como el alcance de las operaciones navales en virtud del valor económico y las amenazas en el entorno marítimo inmediato (International Crisis Group 2016).

\section{Fuerza Aérea de Nigeria}

De acuerdo a la Constitución Política de 1999, el Artículo N. ${ }^{\circ} 1$ del Acta de las Fuerzas Armadas N. 105 de 1993 y los postulados de la Política de Defensa Nacional, las tareas mandatas a la Fuerza Aérea de Nigeria son defender la integridad territorial del país, prestar asistencia a la autoridad civil, proteger los intereses económicos vitales y realizar cualquiera otra función que sea encomendada por ley.

De acuerdo a lo anterior, la última década la Fuerza Aérea de Nigeria ha sido entrenada y equipada para el cumplimiento de múltiples tareas, las cuales van desde la preservación de la paz y operaciones de socorro, hasta 
el apoyo a gobiernos extranjeros aliados en tiempos de crisis. Además, ante una movilización nacional, el poder aéreo puede contribuir decisivamente al éxito en un enfrentamiento bélico, razón por la cual es pertinente reflexionar sobre su papel dentro de la estrategia de defensa de Nigeria.

La doctrina estratégica operacional de la Fuerza Aérea de Nigeria es de carácter defensivo en el sentido de que sus plataformas de combate no poseen una capacidad de destrucción que amenace mayormente a los países vecinos. Sin embargo, posee los complementos para la defensa antiaérea, el apoyo aéreo ofensivo, operaciones navales, transporte ligero y medios suficientes como para disuadir a cualquier agresor dentro de África Occidental (Danbaba 2011).

En cuanto a su arsenal, este vivió un proceso de modernización en virtud del concepto operativo Active Defense...Forward Engagement, el cual si bien considera un número reducido de plataformas de combate, propició el mantenimiento de un poder aéreo táctico que permitiera cumplir con los objetivos de la estrategia de defensa nacional (Danbaba 2011). En este sentido, urge la necesidad de priorizar el desarrollo del poder aéreo, por cuanto el país cuenta con puntos geográficos vulnerables y de gran importancia estratégica como refinerías de petróleo e instalaciones eléctricas, estaciones de generación de energía hidroeléctrica y otras infraestructuras que requieren de una protección efectiva y permanente ante cualquier ataque.

Por otra parte, día a día crecen los retos derivados de compromisos en materia de política exterior, sin embargo, en virtud de la crisis económica, la asignación de recursos al sector defensa no ha aumentado mayormente (Tabla 1). Ante esta realidad, el régimen de Abuja ha optado por crear una fuerza de defensa más compacta, pero bien equipados que sea capaz de responder rápidamente a los desafíos de la seguridad nacional y subregional. 
Tabla 1: Gasto Militar de Nigeria, 2000-2015

\begin{tabular}{|c|c|c|c|}
\hline Año & $\begin{array}{c}\text { Porcentaje de } \\
\text { crecimiento del PIB }\end{array}$ & $\begin{array}{c}\text { Gasto militar como } \\
\text { porcentaje del gasto } \\
\text { público }\end{array}$ & $\begin{array}{l}\text { Gasto militar como } \\
\text { porcentaje del PIB }\end{array}$ \\
\hline 2000 & 5,3 & 2,2 & 0,8 \\
\hline 2001 & 8,2 & 2,5 & 1,3 \\
\hline 2002 & 21,2 & 4,9 & 1,6 \\
\hline 2003 & 10,3 & 2,5 & 0,9 \\
\hline 2004 & 10,6 & 2,7 & 0,7 \\
\hline 2005 & 5,4 & 2,1 & 0,6 \\
\hline 2006 & 6,2 & 2,8 & 0,5 \\
\hline 2007 & 6,4 & 2,0 & 0,6 \\
\hline 2008 & 6,3 & 3,4 & 0,8 \\
\hline 2009 & 6,9 & 3,3 & 0,9 \\
\hline 2010 & 7,8 & 3,2 & 0,5 \\
\hline 2011 & 4,9 & 3,3 & 0,6 \\
\hline 2012 & 4,3 & 3,6 & 0,5 \\
\hline 2013 & 5,4 & 3,5 & 0,5 \\
\hline 2014 & 6,3 & 3,3 & 0,4 \\
\hline 2015 & 2,7 & 3,6 & 0,4 \\
\hline
\end{tabular}

Fuente: Elaboración propia sobre la base de datos de SIPRI (2016), IISS (2016) y $A F D B$ (2015).

Por último, en su afán por transformarse en un líder regional, las operaciones Libertad en Liberia y Sandstorm en Sierra Leona han impulsado en Nigeria el desarrollo de operaciones conjuntas; asimismo, esto se ve potenciado gracias a nuevas adquisiciones: el avión de transporte militar G-222, el helicóptero Super Puma AS322, el avión de combate F-7NI, el helicóptero Agusta 109 y el avión de patrulla marítima ATR 42. Este nuevo equipamiento permitió a Nigeria mejorar la proyección de poder tanto en África Occidental como en todo el continente africano (Dike 2011).

\section{CONSIDERACIONES FINALES}

El breve gobierno Abubakar tuvo el indiscutible mérito de desafiar los privilegios de los militares. En efecto, la promulgación de la Constitución 
Política de 1999 permitió al Ejecutivo nigeriano recuperar parte de sus atribuciones en materia de Defensa Nacional, sin embrago, este logro ha quedado ensombrecido a raíz de las dificultades impuestas por aquellos sectores más radicales de las fuerzas armadas, y que no han dudado en amenazar el orden democrático si sus intereses corporativos se ven afectados.

Esta realidad ha condicionado dramáticamente la reforma del sector defensa impulsada por Obasanjo los dos primeros ańos de su mandato presidencial. Asimismo, los sucesivos gobiernos durante la Cuarta República han sido incapaces de propiciar instancias de concertación política de carácter vinculante con otros actores estatales en la modernización y profesionalización de las Fuerzas Armadas de Nigeria. Paradigmática es la distante relación entre el gobierno y la Asamblea Nacional en el tratamiento de estas cuestiones, la cual ha llevado al gobierno a actuar a través de acciones ejecutivas que dan cuentan del interés en centrar el control de los militares meramente en el Presidente de la República.

Es importante también dotar a las fuerzas armadas de las capacidades y equipamientos necesarios para asumir con éxito las enormes responsabilidades adquiridas en África Occidental. Así, en este caso, la apreciación global política-estratégica debe desarrollarse en consideración de -primero- la política del poder imperante, es decir, la distribución del poder en el sistema internacional; segundo, los procesos políticos internos; tercero, las directrices estratégicas que determinen el sentido de la modernización militar, la capacidad de gestión de esta (relaciones cívicomilitares) y la gradualidad de la misma; y cuarto, la visión que se tiene de la posición del país en el escenario subregional, regional y global.

Finalmente, el futuro de la Cuarta República pasa por establecer una relación de cooperación entre la clase dirigente y los oficiales militares. Esto es muy importante, por cuanto los quiebres democráticos en África no solo responden a la carencia de mecanismos institucionales que regulen las relaciones cívico-militares, sino también a la desconfianza mutua derivada de una gestión gubernamental que ignora consideraciones técnicas en la toma de decisiones y se basa peligrosamente en cuestiones de índole política, étnica o religiosa. 


\section{REFERENCIAS}

Abegunrin, O. (2003). Nigerian Foreign Policy under Military Rule, 19661999, Westport: Praeger.

Abia, V. (2008). Understanding Nigerian Government and Politics. Lagos: Gofaflesh.

Adamolekun, L., Erero, J. y Oshionebo, B. (1991). "Federal Character" and Management of the Federal Civil Service and the Military. Publius, 21 (4), 75-88.

Adejumobi, S. (2010). Democracy and Governance in Nigeria: Between Consolidation and Reversal. En Adejumobi, S. (Ed.), Governance and Politics in Post-Military Nigeria: Changes and Challenges. Nueva York: Palgrave.

Adelegan, F. (2012). Governance: An Insider's Reflections. Bloomington: AuthorHouse.

African Development Bank (AFDB). (2015). African Statical Yearbook 2015. Abidjan: AFDB.

Agbese, P. (2004). Soldiers as Rulers: Military Performance. En Kieh, G. y Agbese, P. (Eds.), The Military and Politics in Africa. Londres: Ashgate.

Akinrinade, S. (2006). An Army Ex-Presidents: Transitions, the Military and Democratic Consolidation in Nigeria. En Southall, R. y Melber, H. (Eds.), Legacies of Power. Leadership Change and Former Presidents in African Politics. Uppsala: HSRC Press.

Assensoh, A. B. y Alex-Assensoh, Y. (2001). African Military History and Politics. Nueva York: Palgrave.

Ball, N. (2010). The Evolution of the Security Sector Reform Agenda. En Sedra, M. (Ed.), The Future of Security Sector Reform. Ontario: The Centre for International Governance Innovation.

Bassey, C. O. (2011). Profesionalisation of Nigeria Armed Forces. En Bassey, C. O. y Dokubo, C. Q. (Eds.), Defence Policy of Nigeria. Capability and Context. Bloomington: AuthorHouse. 
Boege, V., Brown, A., Clements, K. Y Nolan, A. (2009). Gobernanza y Ciudadanía en los Órdenes Políticos Híbridos: Un Cambio de Perspectiva en la Noción de Construcción del Estado. Anuario CEIPAZ, 3, 63-81.

Campbell, J. (2006). Nigeria. Dancing on the Brink. Lanham: Rowman \& Littlefield Publishers, Inc.

Carreño, E. (2016). ¡Soldados, a sus Cuarteles! Hacia una Gobernanza Política en Nigeria. Madrid: UAM Ediciones.

Carreño, E. y Martínez, P. (2016). África Subsahariana en el Orden Internacional. Revista de Occidente, 418, 99-115.

Cawthra, G. (1997). Securing South Africa's Democracy: Defence, Development and Security in Transition. Londres: Palgrave Macmillan.

Cheyre, J. E. (2013) Defense Diplomacy. En Cooper, A. F., Heine, J. y Thakur, R. (Eds.), The Oxford Handbook of Modern Diplomacy. Oxford: Oxford University Press.

Clark, J. (2010). The Decline of the African Military Coup. En Diamond, L. y Plattner, M. (Eds.), Democratization in Africa: Progress and Retreat. Baltimore: The Johns Hopkins University Press.

Cottey, A. y Forster, A. (2004). Reshaping Defence Diplomacy: New Roles for Military Cooperation and Assistance. Londres: The International Institute for Strategic Studies.

Danbaba, B. G. (2011). Air Strategy and the Nigerian Air Force. En Bassey, C. O. y Dokubo, C. Q. (Eds.), Defence Policy of Nigeria. Capability and Context. Bloomington: AuthorHouse.

Decalo, S. (1990). Coups and Army Rule in Africa: Motivations and Constraints. Londres: Yale University Press.

Dike, P. (2011). Nigerian Airforce - Challenges and Response. En Bassey, C. O. y Dokubo, C. Q. (Eds.), Defence Policy of Nigeria. Capability and Context. Bloomington: AuthorHouse

Dokubo, C. (2011). The Nigerian Air Force in a Changing Security Environment. En Bassey, C. O. y Dokubo, C. Q. (Eds.), Defence Policy of Nigeria. Capability and Context. Bloomington: AuthorHouse. 
Edgerton, R. (2002). Africa's Armies. From Honor to Infamy, Boulder: Westview Press.

Elaigwu, I. J. (1997). Military Governance: The Failure of Democracy in Nigeria. En Nwaneri, A. N. (Ed.), Nigeria-Visions for the Future. Ibadan: Macmillan Nigeria.

. (2013). Reinventing the Military as a Political Actor: Alternative Discourses of Civil-Military Relations in Nigeria. En Rüland, J., Manea, M. y Born, H. (Eds.), The Politics of Military Reform. Berlín: Springer-Verlag.

Eleazu, U. (1973). The Role of the Army in African Politics: A Reconsideration of Existing Theories and Practices. The Journal of Developing Areas, 7 (2), 265-286.

Ezenyili, O. K. (2012). Democracy and Good Governance in Nigeria. A Survey of Indices of Transparency and Accountability. Bloomington: AuthorHouse.

Falana, F. (2010). Constitutionalism, Rule of Law, and Human Rights. En Adejumobi, S. (Ed.), Governance and Politics in Post-Military Nigeria: Changes and Challenges. Nueva York: Palgrave.

Fayemi, J. K. (2002). Entrenched Militarism and the Future of Democracy in Nigeria. En Koonings, K. y. Kruijt, D. (Eds.), Political Armies: The Military and Nation Building in the Age of Democracy. Nueva York: Zed Books.

Fayemi, J. K. (2005). Constitutionalizing Security Sector Reform in Nigeria: Context and Issues. En. Igbuzor, O. e Ibrahim, J. (Eds.), $A$ Citizens Approach to Making a People's Constitution in Nigeria. Lagos: Citiz Forum Constitutional Reform.

Fayemi, J. K. y Olonisakin, 'F. (2008). Nigeria. En Bryden, A., N'Diaye, B. y Olonisakin,'F. (Eds.), Challenges of Security Sector Governance in West Africa. Ginebra: Geneva Centre for the Democratic Control of Armed Forces.

Finer, S. (1962). The Man on Horseback: The Role of the Military in Politics. Londres: Pall Mall Press. 
Garba, K. (2008). Nigeria. En Ebo, A. y N’Diaye, B. (Eds.), Parliamentary Oversight of the Security Sector in West Africa: Opportunities and Challenges. Ginebra: Centre for the Democratic Control of the Armed Forces.

Gould, M. (2013). The Biafran War: The Struggle for Modern Nigeria. Nueva York: I. B. Tauris.

Hayner, P. (2008). Verdades Innombrables. El Reto de las Comisiones de Verdad. Ciudad de México: Fondo de Cultura Económica.

Houngnikpo, M. (2013). Guarding the Guardians. Civil-Military Relations and Democratic Governance in Africa. Burlington: Ashgate.

Ibeanu, O. y Egwu, S. (2007). Popular Perception and Political Government. Lagos: Centre for Democracy and Development.

Ibrahim, O. S. (2011). Maritime Strategy and the Nigerian Navy. En Bassey, C. O. y Dokubo, C. Q. (Eds.), Defence Policy of Nigeria. Capability and Context. Bloomington: AuthorHouse.

Ihonvbere, J. y Shaw, T. (1998). Towards a Political Eonomy of Nigeria. Brookfield: Grower Publishing Company.

International Institute for Strategic Studies (IISS). (2016). The Military Balance 2016. Londres: IISS.

International Crisis Group (2016). Nigeria: The Challenge of Military Reform. Africa Report, 237.

International Institute for Democracy and Electoral Assistance (2000). Democracy in Nigeria: Continuing Dialogue(s) for Nation-Building. Estocolmo: I-IDEA.

Janowitz, M. (1964). The Military in the Political Development of New Nations. Chicago: University of Chicago Press.

Johnston, A. I. (1995). Thinking about Strategic Culture. International Security, 19 (4), 32-64.

Kieh, G. (2004). Military Engagement in Politics in Africa. En Kieh, G. y Agbese, P. (Eds.), The Military and Politics in Africa. Londres: Ashgate. 
Manea, M. G. y Rüland, J. (2013). Taking Stock of Military Reform in Nigeria En Rüland, J., Manea, M. y Born, H. (Eds.), The Politics of Military Reform. Berlín: Springer-Verlag.

Nathan, L. (1997). Lethal Weapons: Why Africa Needs Alternatives to Hired Guns. Track Two, 6 (2), 10-12.

Nwagwu, 'E. (2002). Taming the Tiger. Civil-Military Relations Reforms and the Search for Political Stability in Nigeria. Lanham/Maryland: University Press of America, Inc.

Nwankwo, B. O. (2003). Institutional Design and Functionality of African Democracies. A Comparative Analysis of Nigeria and Uganda. Berlín: Tenea Verlag für Medien.

Nwolise, O. B. C. (2002). Democratic Control of the Military: The Nigerian Experience. Nigerian Forum, 23 (11-12), 314-335.

Ogundiya, I. S. (2010). Democracy and Good Governance: Nigeria’s Dilemma. African Journal of Political Science and International Relations, 4 (6), 201-208.

Oke, L. (2010). Democracy and Governance in Nigeria’s Fourth Republic. African Research Review, 4 (3), 31-40.

Olonisakin, F. (1999). Democratic Transition in Nigeria: Will the Military Stay out of Politics? Africa Insight, 29 (1-2), 19-35.

Omoigui, N. (sin fecha). History of Civil-Military Relations in Nigeria. Disponible en http://www.dawodu.com [20-10-2016].

Organization for Economic Cooperation and Development (2005). Security System Reform and Governance: A DAC Reference Document. Disponible en https://www.oecd.org/dac/governancepeace/conflictfragilityandresilience/docs/31785288.pdf [31-10-2016].

Reno, W. (2011). Warfare in Independent Africa. Nueva York: Cambridge University Press.

Sanusi, H. U. (2011). Defence Management in the Ministry of Defence. En Bassey, C. O. y Dokubo, C. Q. (Eds.), Defence Policy of Nigeria. Capability and Context. Bloomington: AuthorHouse. 
Sedra, M. (2010). Introduction: The Future of Security Sector Reform. En Sedra, M. (Ed.), The Future of Security Sector Reform, Ontario: The Centre for International Governance Innovation.

Stockholm International Peace Research Institute (SIPRI). (2016). SIPRI Military Expenditure Database. Disponible en https://www.sipri.org/ databases/milex [31-10-2016].

Suberu, R. T. (2010). Nigeria's Muddled Elections. En Diamond, L. y Plattner, M. F. (Eds.), Democratization in Africa. Progress and Retreat. Baltimore: The Johns Hopkins University Press.

Ugoh, S. C. (2005). Constitution-Making and Constitutionalism in Nigeria's Fourth Republic (1999-2004): Issues and Trends. UNILAG Journal of Politics, 2 (1), 154-179.

Ukpabi, S. C. (1976). The Changing Role of the Military in Nigeria, 1900-1970. África Spectrum, 11 (1), 61-77.

UN/Secretary-General (2008). Securing Peace and Development: The Role of the United Nations in Supporting Security Sector Reform. Disponible en http://www.un.org/en/ga/search/view_doc. asp?symbol=S/2008/39 [31-10-2016].

United Nations Trust Fund for Human Security (2009). Human Security in Theory and Practice. Disponible en http://www.un.org/ humansecurity/sites/www.un.org.humansecurity/files/human_ security_in_theory_and_practice_english.pdf [31-10-2016].

Van Nieuwkerk, A. (2014). Security Sector Reform in Africa. En Hentz, J. J. (Ed.), Routledge Handbook of African Security. Nueva York: Routledge.

Yoroms, G. (2005). Security Sector Governance in Nigeria. En Eze, O. y Hettmann, J. (Eds.), Security Sector Governance in West Africa. Lagos: Frankad.

Recibido: 03-10-2016

Aceptación de la versión final: 02-11-2016 